\title{
Metodologias ativas e interdisciplinaridade no ensino da infografia
}

\section{Active methodologies and interdisciplinarity in the teaching of computer graphics}

\author{
Rangel Sales, Júlio Alessi e Akemi Ishihara.
}

Interdisciplinaridade, metodologias ativas, infografia

\begin{abstract}
Este estudo propõe a discussão sobre a utilização da interdisciplinaridade e de metodologias ativas no ensino da infografia. Nesse sentido, o estudo tem por objetivo geral atualizar as práticas ativas educacionais e, em termos específicos, contribuir para a formação de profissionais de design gráfico alinhados às necessidades pós-modernas. Para desenvolver tal proposta, pressupõe-se que a utilização de metodologias ativas poderiam contribuir para desenvolver habilidades e competências aos futuros profissionais em design relacionadas à solução de problemas de maneira inovadora e interdisciplinar. Para esta publicação, foi realizado um estudo de caso sobre o Trabalho Interdisciplinar de Graduação (TIG-II), disciplina que compõe a grade curricular do curso tecnológico em design gráfico, oferecido pelo Centro Universitário de Belo Horizonte (UniBH), realizado no segundo semestre de 2015. Ao final, observou-se que a partir das ações conjugadas das disciplinas ministradas durante o módulo, bem como a utilização de metodologias ativas, foram obtidos resultados consonantes com as atuais exigências profissionais do mercado editorial.
\end{abstract}

Interdisciplinarity, active methodologies, computer graphics

This study proposes the discussion on the use of interdisciplinarity and active methodologies in infography teaching. In this sense, the main objective of the study is to update active educational practices and, in specific terms, to contribute to the training of graphic design professionals aligned with postmodern needs. In order to develop such a proposal, it was assumed that the use of active methodologies could contribute to the development of skills and competences for future design professionals related to problem solving in an innovative and interdisciplinary way. For this publication, a case study on the Interdisciplinary Work of Graduation (TIG-II), a discipline that composes the curricular grid of the tecnological course in graphic design, offered by the University Center of Belo Horizonte (UniBH) was carried out in the second semester of 2015. In the end, it was observed that from the combined actions of the disciplines taught during the module, as well as the use of active methodologies, results were obtained consonant with the current professional requirements of the publishing market.

\section{Introdução}

O campo de atuação profissional dos egressos dos cursos da área de comunicação visual transpassa pelas mais diversas possibilidades de produção. Dentre elas, identifica-se a infografia como linguagem de muita importância em um contexto de hibridação de mídias, e um universo de informações complexas em diversos contextos midiáticos como sites de notícia, livros didáticos, revistas digitais e impressas e aplicativos para dispositivos móveis. A função básica da infografia segundo Moraes (2013) é de através da arte tornar uma informação complexa em algo simples com uma organização visual atrativa.

A partir deste princípio, foi desenvolvida uma experiência com duas turmas do curso tecnológico em Design Gráfico do Centro Universitário de Belo Horizonte: A utilização de metodologias ativas para o ensino da infografia, a fim de preparar tais discentes para situações reais de mercado. A proposta é resultado da prática interdisciplinar que, nesta instituição, é denominada Trabalho Interdisciplinar de Graduação do Segundo Módulo. (TIG-II). Todas as disciplinas convergiram, pois, na produção de materiais gráficos visuais não verbais para comporem, ao fim do semestre, um livro composto exclusivamente por infográficos de temas pré-definidos.

Mais que preparar o estudante para atuar no mercado de maneira proficiente, é necessário que

Anais do8CIDI e 8CONGIC

Guilherme Santa Rosa; Cristina Portugal (orgs.)

Sociedade Brasileira de Design da Informação - SBDI

Natal | Brasil |2017

ISBN 978-85-212-1305-5
Proceedings of the $8^{\text {th }} \mathrm{CIDI}$ and $8^{\text {th }}$ CONGIC

Guilherme Santa Rosa;Cristina Portugal (orgs.)

Sociedade Brasileira de Design da Informação - SBDI

Natal| Brazil |2017

ISBN 978-85-212-1305-5 
os cursos de formação profissional preparem-no para pensar o design de maneira diferenciada. A formatação do TIG-II, ao estimular a experimentação e a prática de linguagens verbais e não verbais, considerando a inovação e versatilidade dos futuros designers gráficos, proporcionando aos discentes sua expansão profissional.

Nesse sentido, faz-se necessária a utilização de estratégias comunicacionais inovadoras que incentivem aos discentes a se adaptarem às diversificadas situações nas quais sua práticas profissionais lhe exigirão. Surge pois, a necessidade da formação de um indivíduo cujas ações sejam versáteis e, que nesse sentido, esteja apto a solucionar problemas comunicacionais que ainda não existam. Propõe-se a utilização de metodologias ativas nas quais a prática docente seja permeada por uma série de atividades elaboradas a partir de situações de resolução de problemas reais, cujas soluções estejam em consonância com as necessidades do campo profissional.

\section{Metodologias ativas e a interdisciplinaridade}

A contemporaneidade é representada por mudanças significativas na constituição da sociedade, bem como na maneira pela qual o indivíduo se comporta diante de situações profissionais. Faz-se necessária pois, uma readequação das metodologias educacionais responsáveis para a formação desse indivíduo para este novo cenário. Nesse sentido, surge a proposta pedagógica proposta pelo Conselho Nacional de Educação (2001), que apontam para a formação de um profissional apto a solucionar problemas em níveis individuais ou coletivos, bem como tomar decisões apropriadas ao exercício da liderança, da administração e do gerenciamento.

Entende-se, portanto, que Metodologias Ativas baseiam-se em formas de desenvolver o processo de aprendizado, a partir da utilização de experiências reais ou simuladas, objetivadas pela condição de solucionar, com êxito, desafios provenientes das atividades fundamentais para o exercício da prática social em diferentes contextos.

De acordo com os estudos de Berbel (2011) os reflexos da utilização das Metodologias Ativas no processo contemporâneo de ensino proporciona situações experienciais motivadoras aos discentes:

O engajamento do aluno em relação a novas aprendizagens, pela compreensão, pela escolha e pelo interesse, é condição essencial para ampliar suas possibilidades de exercitar a liberdade e a autonomia na tomada de decisões em diferentes momentos do processo que vivencia, preparando-se para o exercício profissional futuro. Para isso, deverá contar com uma postura pedagógica de seus professores com características diferenciadas daquelas de controle. (Berbel, 2011, p.29)

Propõe-se, por este viés, uma experiência teórico-empírica para os projetos interdisciplinares, ao passo em que deverão por sua essência de multiplicidade de situações nas quais o discente deverá solucionar problemas contextualizados à sua praxis. As Metodologias Ativas seriam, nesse sentido, uma fração fundamental para fomentar situações nas quais esse futuro profissional deverá lidar no futuro.

Todo esse contexto no mundo do trabalho interferirá diretamente na escola e nos sistemas e processos de ensino aprendizagem. Os educadores deverão diagnosticar e não adivinhar, pressagiar, agourar as novas competências e habilidades necessárias para essa nova conjuntura. As soluções devem ser adaptáveis, escaláveis, disponíveis sob demanda para que os estudantes possam acessá-las no melhor momento para eles. Fava (2016, p. 264).

É de vital importância uma alinhamento entre as instituições de ensino e o mercado de trabalho de hoje e principalmente o mercado do futuro, já que nossos discentes serão os futuros profissionais que devem estar aptos às novas demandas em um contexto multidisciplinar de trabalhos em equipes. 
Isto posto, não é possível hoje enxergar e tratar da mesma forma tradicional, os envolvidos nas dinâmicas de ensino e aprendizagem. Não há mais espaço para relações verticalizadas, nas quais os discentes seriam apenas receptores do conhecimento rotineiro e pragmático, a partir da transmissão feita por um professor hierarquizado e burocrático. Percebe-se pois, a necessidade constante de se inventar e reinventar o cotidiano, abrindo e repensando novas possibilidades e paradigmas. Essas reflexões apontam para, segundo Fontoura (2011), uma superação de formas tradicionais de pensamento, enquadradas nos domínios da disciplinaridade.

\section{Projeto interdisciplinar de graduação do segundo módulo (TIG-II)}

A vigente matriz curricular do Centro Universitário de Belo Horizonte (UniBH), propõe que semestralmente sejam realizados projetos interdisciplinares com temas em consonância com as disciplinas lecionadas naquele módulo. O objetivo dessa proposta é possibilitar aos discentes desenvolverem projetos teórico-práticos que reúnam todo conteúdo abordado durante aquele semestre. Os temas são direcionados às unidades de formação e cada semestre uma área específica do conhecimento é trabalhada a partir do viés das disciplinas do mesmo período. Conhecido inicialmente como Trabalho Interdisciplinar de Graduação (TIG), após a reformulação da matriz curricular proposta em 2015, passou a chamar-se Projeto Interdisciplinar (PI). Contudo, mantém os mesmo moldes de propostas, execução e critérios de avaliação.

Todas as orientações, normas de distribuição de notas, bem como os critérios de avaliação são descritos pelo edital do TIG / PI, documento redigido de maneira colaborativa e cooperativa com o corpo docente do módulo no qual o projeto será proposto, sendo revisado e validado por esta equipe e pela coordenação. Esse documento é disponibilizado aos discentes para que tenham conhecimento sobre os procedimentos referentes ao projeto daquele semestre.

Nesse sentido, foi proposto o desenvolvimento do projeto Livro de infografias. O projeto corrobora com o ementário de todas as disciplinas ministradas durante o terceiro módulo do curso Tecnológico em Design Gráfico pois desenvolve um projeto complexo que envolve ações relacionadas aos conteúdos das disciplinas: Layout Gráfico, Edição e Tratamento de Imagens, Ilustração Gráfica, Tipografia, Software Aplicado ao Design Editorial, Fotografia. Todos os conteúdos foram alinhados e direcionados para que cada disciplina contribuísse massivamente para o planejamento, produção e realização de livro com acabamento gráfico e estrutura editorial adequados às necessidades do mercado atual. O Edital do TIG-II define também a contribuição de cada um destes conteúdos como vê-se a seguir:

A disciplina Layout Gráfico abordará temas relacionados à composição visual, gestalt e técnicas de comunicação visual aplicada.

A disciplina Edição e tratamento de imagens contribuirá na orientação na construção e planejamento visual gráfico das imagens digitais.

A disciplina llustração gráfica contribuirá no desenvolvimento de diversas possibilidades de materiais e orientação para a criação das ilustrações que serão utilizadas nos infográficos.

A disciplina Tipografia contribuirá na orientação relacionada à escolha das tipografias utilizadas nos layouts desenvolvidos, tanto teórica quanto prática.

A disciplina Software aplicado ao design editorial contribuirá com a padronização e layout digital do arquivo, criação dos estilos, imposição automática e geração dos arquivos para impressão.

A disciplina Fotografia irá contribuir na orientação do uso da fotografia na construção dos infográficos do TIG e também no uso das linguagens visuais em relação a linguagem verbal através dos estudos da teoria da intermidialidade proposta por Cluver. (UniBH, 2015, p.8-9) 


\section{CIDI 2017}

\section{4. $O$ livro de infografias}

A proposta para a edição do TIG-II desenvolvido pelo segundo módulo do curso tecnológico em Design Gráfico do UniBH para o segundo semestre de 2015 foi realizar um projeto que pudesse integrar habilidades e competências para o atendimento a necessidades de um cliente real. Ademais, a proposta deveria fomentar ações comunicacionais e que fizessem uso de técnicas variadas de ilustração e manipulação de imagens pelos discentes ao passo em que seus projetos estivessem em plena consonância com as atuais e futuras necessidades de mercado. $O$ produto gráfico escolhido para sintetizar as necessidades e desafios propostos para este projeto foi um um livro, pois assim como afirma Haslam (2007), o livro impresso ainda se mostra expressivo para a disseminação de ideias.

O livro deveria pois, estar configurado sob as seguintes especificações: formato: $20 \times 20 \mathrm{~cm}$, impresso a $4 \times 4$ cores, em papel do tipo couché fosco pesando $145 \mathrm{gramas} / \mathrm{cm}^{2}$, recebendo o acabamento gráfico de lombada quadrada e capa dura. A publicação deveria possuir, no mínimo, 24 páginas incluindo a sessão pré-textual. A partir destas especificações técnicas a proposta estende-se pela produção de gráficos que não só ornamentem o projeto, mas sim criem uma proposta de unidade visual para o projeto gráfico, conforme determina o Edital do TIG-II, que direciona todas as ações dos docentes e discentes atuantes neste módulo.

O produto final será uma coleção de livros abordando aspectos do design por meio de infográfico abordando linguagens verbais e não verbais; O livro deverá ser composto pela parte pré-textual, que envolve folha de rosto, ficha catalográfica e sumário; As guardas das capas deverão conter padronagens ou gráficos que compuserem a identidade visual do livro; Deverá ser produzida uma apresentação multimídia do trabalho, que contenha traços da identidade visual do projeto. Para a apresentação oral, todos os grupos deverão imprimir DOIS LIVROS, UM PARA REGISTRO DO CURSO e outra para portfólio dos alunos, que fará parte da avaliação e que ficará exposto durante o Circuito Acadêmico, evento que objetiva partilhar o trabalho desenvolvido pelos grupos durante 0 período. (UniBH, 2015, p.6)

Além de um conjunto de normas técnicas no tangente à diagramação, identidade visual e acabamento, a publicação deveria ser composta de uma série de infográficos produzidos a partir de um conjunto diversificado de técnicas de ilustração e manipulação de imagens, bem como abordarem uma relação específica de temas pré-determinados:

- Front-end / Ux Design

- Design gráfico digital e analógico: semelhanças e diferenças

- Classificação ATYPL e os usos das famílias tipográficas no design

- As Categorias conceituais fundamentais da Gestalt aplicadas ao design de embalagens ou pontos de venda

- Evolução da tecnologia na fotografia

- Evolução da tecnologia na produção de livros

- Comparativo editoração de revistas - Design Moderno e Design Pós Moderno

- Design de superfície aplicado em design de moda

- Design universal

O uso de infográficos no projeto interdisciplinar, deu a oportunidade de articular conteúdos e técnicas de três área: design, ilustração e informação. Possibilitando aos estudantes sintetizar os conteúdos estudados nas disciplinas em diagramas gráfico-textuais fazendo o uso das linguagens da fotografia e ilustração. Foi realizado em paralelo ao projeto do TIG a construção de alguns infográficos de conteúdos específicos de algumas disciplinas do semestre como a fotografia, no qual os alunos tiveram que construir infográficos de técnicas aprendidas em sala.

\subsection{Oficinas e aulas práticas}

Foram propostas para esta edição do TIG-II uma série de oficinas e aulas práticas para que os discentes pudessem desenvolver suas habilidades e competências no que tange a resolução de problemas a partir de situações reais com o auxílio de profissionais de mercado. Para a produção dos livros de infografias, foram realizadas oficinas de ilustração e infografia, encadernação e acabamento, imposição de páginas e fechamento de arquivos.

Para a oficina de ilustração e infografia foram convidados dois profissionais responsáveis pelo departamento de artes do Jornal o Tempo, segundo maior veículo de mídia impressa do estado de Minas Gerais. A prática abordou temas como técnicas de ilustração e manipulação digital, 


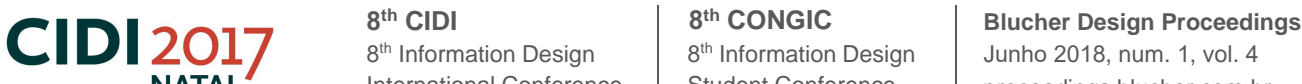

diagramação, utilização de recursos experimentais e comunicação visual. Foi proposto aos discentes que elaborassem, a partir dos princípios abordados durante a oficina, infográficos utilizando apenas recursos manuais. Por fim as propostas seriam pois, finalizadas digitalmente.

Figura 1: Oficina de ilustração e infografia ministrada por profissionais do mercado editorial de Belo Horizonte.
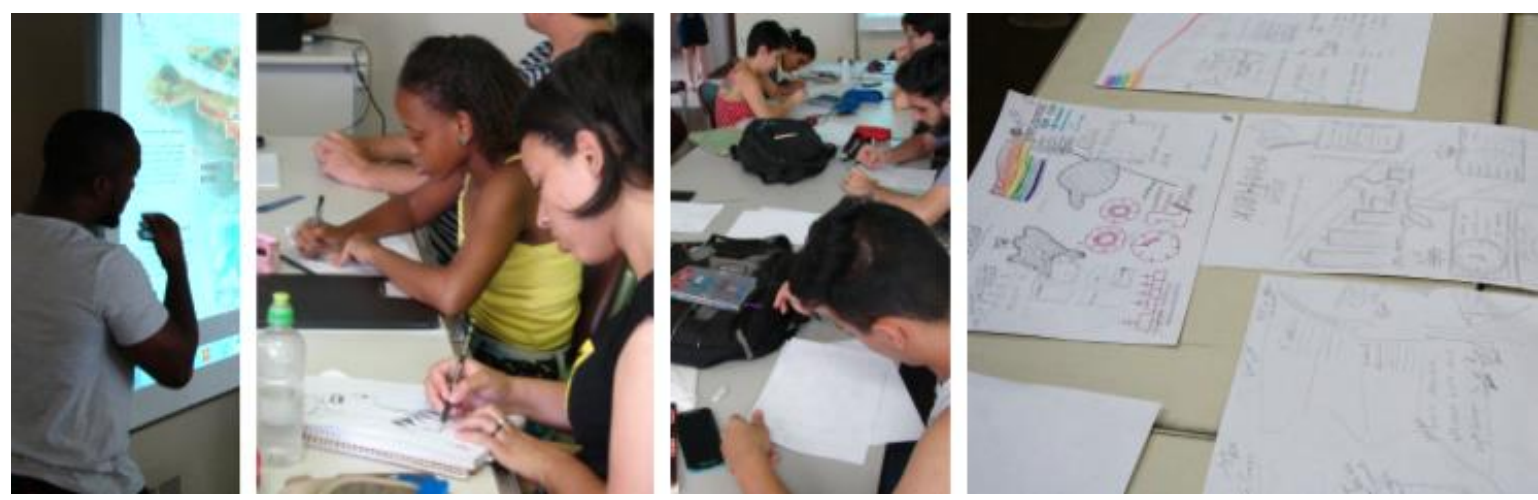

No segundo momento, foi realizada a oficina de encadernação artesanal, para que os discentes se familiarizassem com os termos técnicos e partes que compõem um livro. A oficina foi ministrada pelo orientador do TIG-II, cuja formação engloba Design Gráfico em nível técnico e especialização em Projetos Editoriais.

Por fim, foi realizada a última prática para a produção dos projetos editoriais em infografia: a oficina de imposição de páginas e fechamento de arquivos. Outras questões também foram abordadas durante essa prática, tais como prazos de produção, contato com fornecedores e preparação de arquivos digitais aos sistemas de impressão utilizados.

Os projetos práticos deram ênfase aos processos manuais no intuito em desenvolver as habilidades necessárias a prática projetual do design da informação, com prototipações de baixa fidelização e validação do projeto com pequenos grupos focais, para diagnosticar possíveis problemas no tratamento da informação nos infográficos produzidos.

Figura 2: Exemplos de prototipações de baixa fidelização para desenvolver os infográficos.

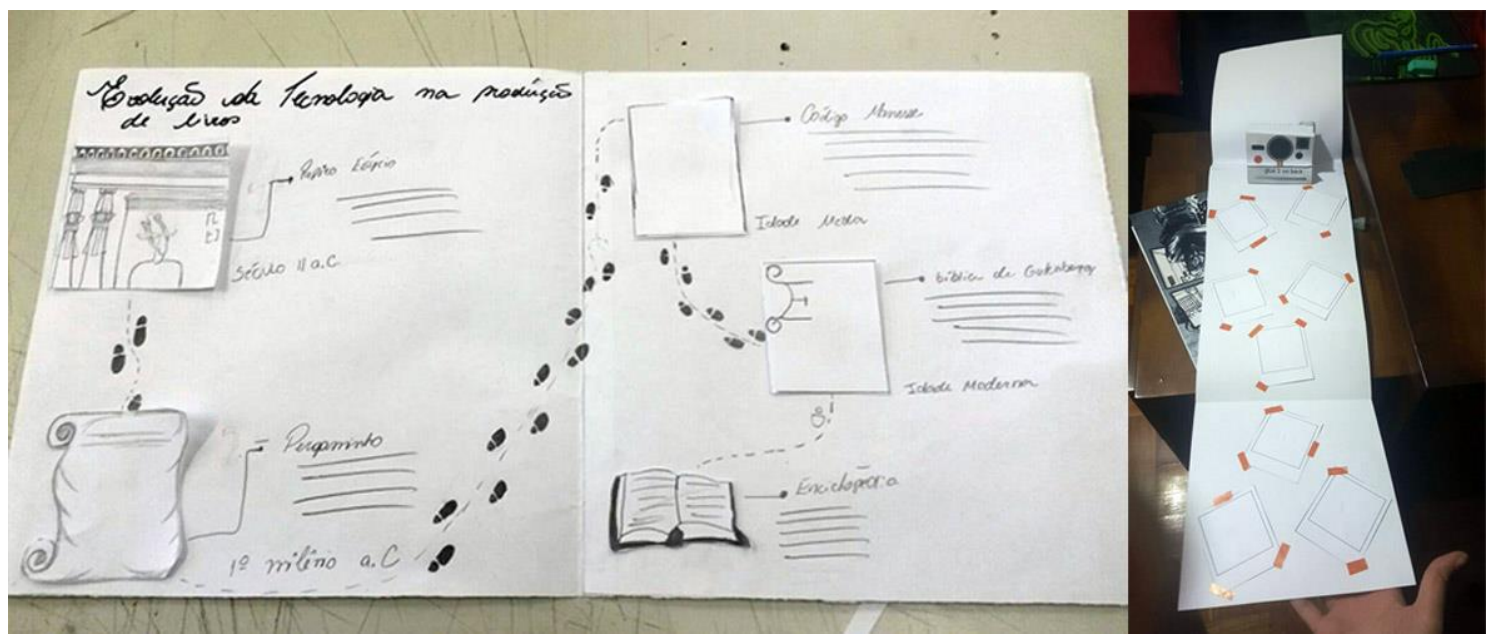

Os alunos utilizaram ainda, técnicas de fotografia para construir algumas opções de layout de forma rápida, na qual se pudesse manipular facilmente os elementos dentro do grid proposto, facilitando assim o processo criativo em grupo. 


\section{\begin{tabular}{ll|l|l} 
C1D 2017 & $8^{\text {th }}$ CIDI & $\begin{array}{l}8^{\text {th }} \text { CONGIC } \\
8^{\text {th }} \text { Information Design }\end{array}$ & $\begin{array}{l}\text { Blucher Design Proceedings } \\
\text { Junho 2018, num. 1, vol. 4 }\end{array}$
\end{tabular}}

Figura 3: Exemplos de prototipações com o uso da fotografia, ilustrações e objetos.

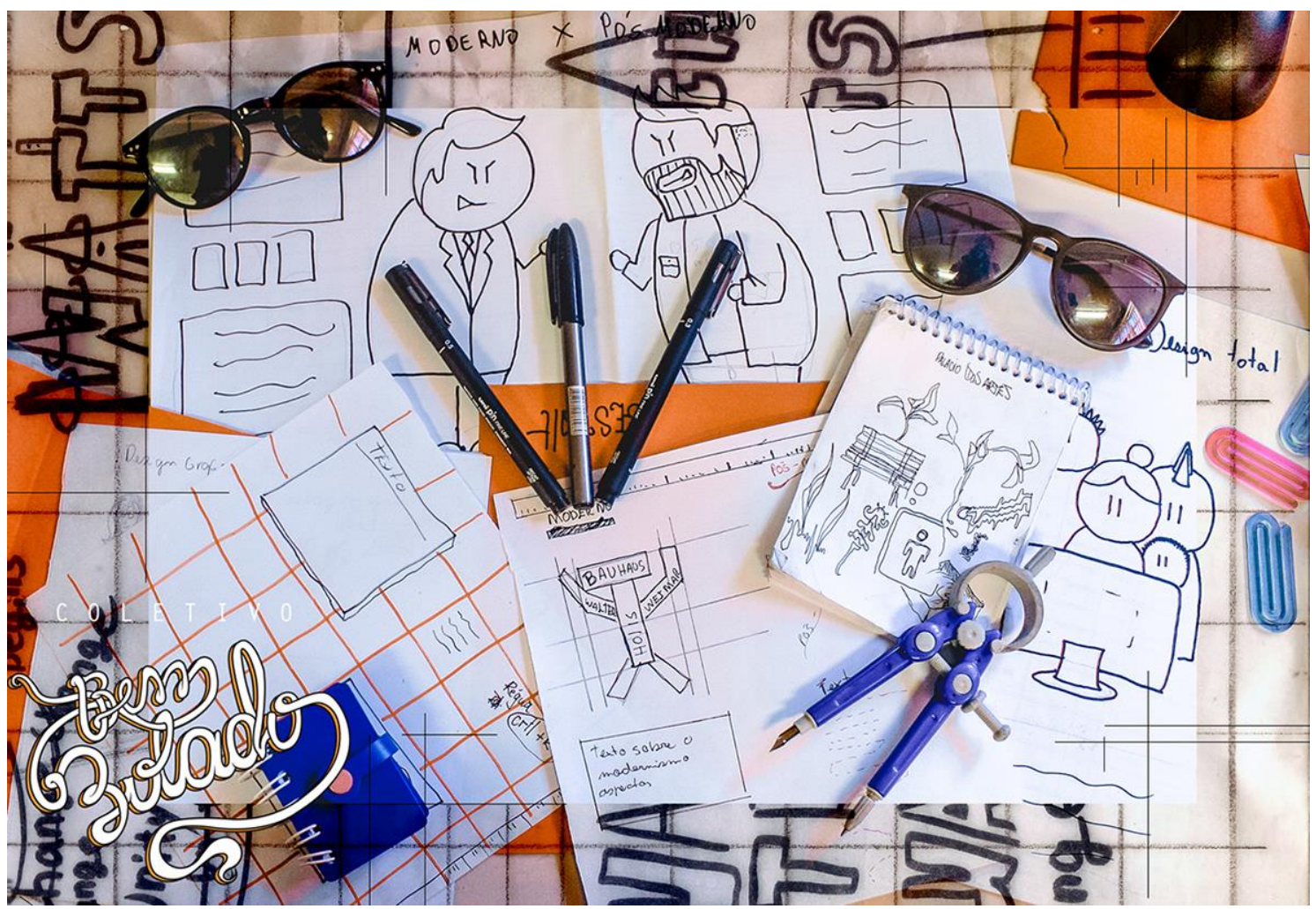

\section{Circuito Acadêmico}

Semestralmente, é realizado uma das maiores mostras de trabalhos acadêmicos do estado de Minas Gerais: O Circuito Acadêmico. O evento reúne todos os TIGs e Pls desenvolvidos pelos discentes do UniBH na maioria das áreas do conhecimento. Aos moldes da proposta de Emar de Almeida \& Sales de Almeida (2016), realizada durante a edição do primeiro semestre de 2015 , foi concedido um espaço de $27 \mathrm{~m}^{2}$ no qual os projetos puderam ser exibido ao público do evento. As equipes apresentaram o material impresso, além de um banner no qual estava resumido todo projeto. $O$ formato de apresentação simulando uma exposição busca maior visibilidade aos projetos elaborados pelos discentes.

O processo avaliativo contou com duas etapas, conforme propõe o edital que regulamenta a disciplina TIG-II. Na primeira, os discentes apresentaram seus projetos finalizados digitalmente para uma banca avaliadora composta por professores e pelos profissionais que proferiram as oficinas no decorrer do semestre. Nessa etapa, a banca avaliadora apontou as não conformidades resultantes do processo utilizados pelos discentes e propuseram as adequações necessárias para que os projetos estivessem alinhados às necessidades comunicacionais do mercado editorial atual. Os discentes realizaram as alterações necessárias e, por fim, produziram os livros de infográficos com acabamento profissional para serem apresentados aos avaliadores e ao público durante o Circuito Acadêmico. No segundo momento, a banca avaliadora revisou minuciosamente os projetos apresentados durante 0 evento acadêmico e fez suas observações sobre o acabamento editorial e sua qualidade visual gráfica e comunicacional. 


\section{\begin{tabular}{ll|l|l} 
CDI 2017 & $8^{\text {th }}$ CIDI & $8^{\text {th }}$ CONGIC & Blucher Design Proceedings \\
$8^{\text {th }}$ Information Design & $8^{\text {th }}$ Information Design & Junho 2018, num. 1, vol. 4
\end{tabular}}

NATAL gel Salernational Conference Ake Stitudent Confer

Figura 2: As duas etapas do processo de avaliação dos trabalhos do TIG-II realizada por professores e profissionais profissionais do mercado editorial de Belo Horizonte.
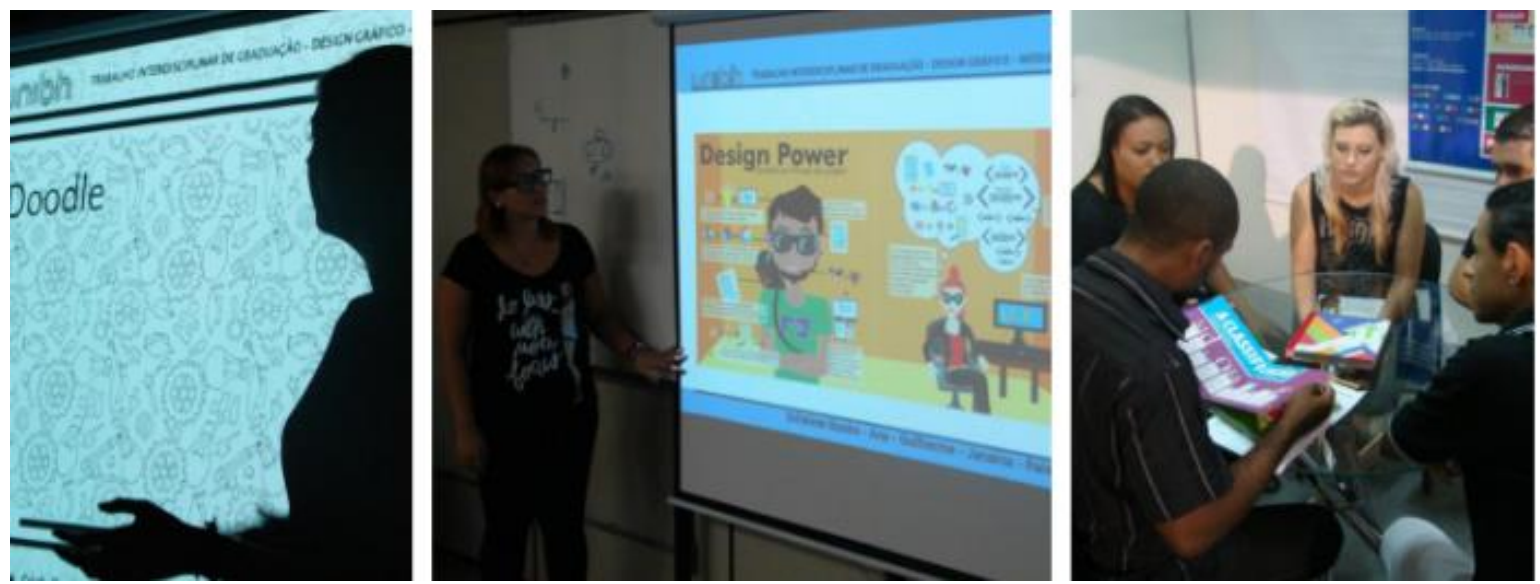

A partir da utilização dos princípios da interdisciplinaridade propostos por Rancière (2005), bem como da utilização de metodologias ativas segundo Berbel (2011) e por fim, gerando um produto editorial em consonância com os fundamentos propostos por Ambrose \& Harris (2009) e Samara (2011), obtém-se pois um conjunto de publicações elaboradas a partir de práticas inovadoras de um grupo de discentes que não havia produzido nenhuma publicação com tal complexidade.

Foram produzidos um total de 11 livros com formatos padronizados mas com algumas variações no acabamento, incluindo revestimento em tecido. Apesar desta variação, o resultado seguiu às normas de produção gráfica resultando numa publicação com aspecto profissional. Para os infográficos, foi permitido que os discentes utilizassem seus estilos próprios de ilustração sem limitação de técnicas, o que resultou em infográficos inovadores e esteticamente diferenciados.

Figura 3: Alguns dos resultados obtidos na disciplina TIG-II a partir da utilização de metodologias ativas.
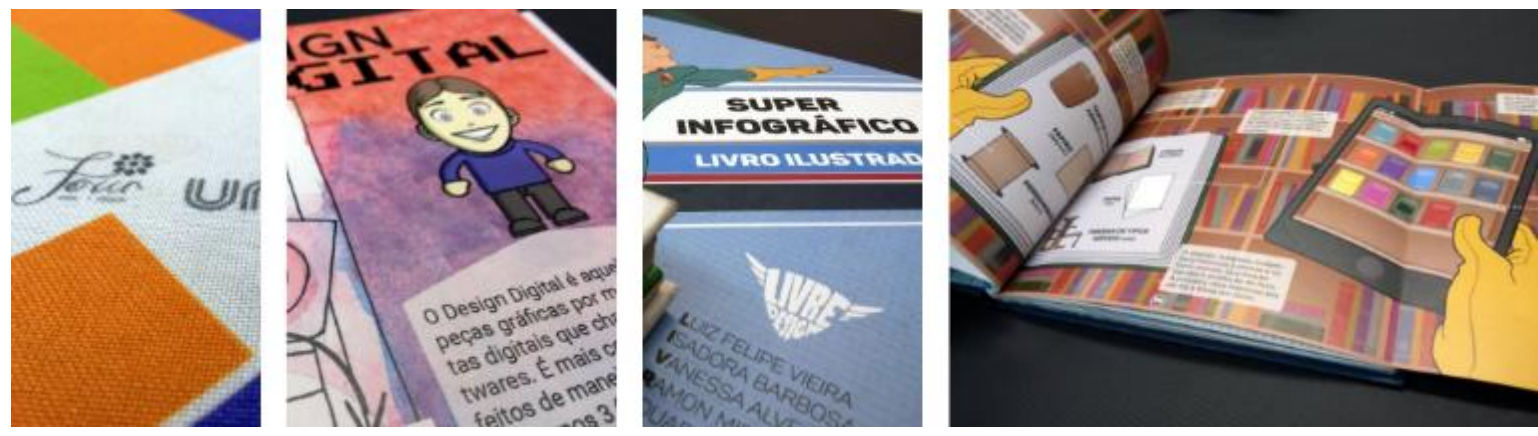

\section{Considerações finais}

Os resultado obtidos por meio desta proposta de trabalho interdisciplinar só foi possível graças à integração da equipe docente, bem como o alinhamento das ações das disciplinas e suas contribuições para o projeto. A prática profissional do designer faz-se interdisciplinar por natureza, visto que este profissional integrará ou coordenará equipes de profissionais das mais variadas formações, com diversificadas habilidades e competências.

Há de se considerar a utilização de metodologias ativas não só no ensino do design, mas no ensino como um todo. Para o design, a tais metodologias proporcionam a experimentação, o aprendizado experiencial e, sobretudo, a vivência com situações nas quais os futuros designers deverão propor soluções inovadoras a partir de solução de problemas reais.

A partir das práticas abordadas por este estudo, percebeu-se que os discentes puderam fazer uso de técnicas experimentais agregadas a técnicas convencionais, todos monitorados e 


\section{CIDI 2017}

mentorados por docentes e profissionais de comunicação e ilustração reconhecidos pelo campo profissional.

Não é pretensão destes pesquisadores proporem soluções altamente relevantes para a utilização de metodologias ativas no ensino da infografia, tampouco listar os procedimentos definitivos para o emprego da interdisciplinaridade no ensino do design. Contudo, há de se propor e avaliar novas modalidades educacionais para o design gráfico, bem como preparar os futuros profissionais em infografia para solucionar os problemas comunicacionais conhecidos e aqueles que ainda estão por vir.

\section{Referências}

AMBROSE, Gavin \& HARRIS, Paul. 2009. Impressão e acabamento. Porto Alegre: Bookman.

BERBEL, Neusi Aparecida Navas. 2011. As metodologias ativas e a promoção da autonomia de estudantes. Semina: Ciências Sociais e Humanas, Londrina, v. 32, n. 1, p. 25-40, jan./jun.

EMAR DE ALMEIDA, Délcio Julião \& SALES DE ALMEIDA, Rangel Benedito. 2016 Projeto exposições itinerantes: a interdisciplinaridade e a inovação no ensino de design, p. 22122223 . In: Anais do $12^{\circ}$ Congresso Brasileiro de Pesquisa e Desenvolvimento em Design [= Blucher Design Proceedings, v. 9, n. 2]. São Paulo: Blucher.

CLUVER, Claus. Estudos interartes: conceitos, termos, objetivos. Literatura e sociedade. São Paulo: USP, 1997.FAVA, Rui. Educação para o século XXI: a era do indivíduo digital. São Paulo: Saraiva, 2016.

FONTOURA, Antônio. M. 2011. A interdisciplinaridade e o ensino do design. Projética Revista Científica de Design, Universidade Estadual de Londrina, v.2, ํㅡ. 2, Dezembro.

HASLAM, Andrew. 2007. O livro e o designer II: como criar e produzir livros. São Paulo: Edições Rosari.

HORIE, Ricardo Minoru. 2003. Preparação e fechamento de arquivos para birôs.São Paulo: Érica.

MORAES, Ary. Infografia: história e projeto. São Paulo: Blucher, 2013.

RANCIÈRE, Jacques. 2005. A partilha do Sensível: estética e política. São Paulo: EXO experimental org.: Ed. 34, $72 \mathrm{p}$.

SAMARA, Timothy. 2011. Guia de design editorial: manual prático para o design de publicações. Porto Alegre: Bookman

UNIBH. Centro Universitário de Belo Horizonte. 2015. Edital do Trabalho Interdisciplinar de Graduação - Tecnológico em Design Gráfico - Módulo II. Belo Horizonte: Segundo semestre.

Rangel Sales; Mestre, UNIBH, Brasil <rangel@rangelsales.com.br>

Julio Alessi; Mestre, UNIBH, Brasil <juliolafeta@gmail.com>

Akemi Ishihara; Mestre, UNIBH, Brasil <Akemi.i.a@gmail.com> 